\title{
Improving Fishery Management Models and Methods
}

\author{
Ingólfur Arnarson*, Páll Jensson**
}

\begin{abstract}
For nearly six decades, fishery managers and policy makers have used bio-economic models and methods as the foundation for their management schemes. These models and methods are for the most part based on the deductive methodology of economics where central assumptions are the metaphors of "equilibrium" and "bio-economic equilibrium". Models based on equilibrium theories are usually deterministic and static whereas the dynamics of the operations and the markets are a meager part of the problem. Less attention has been offered to inductive reasoning and modeling within the field of fishery management. The inductive method of reasoning is often based on facts and actual observations within the industries, a methodology widely used by engineers and the field of business administration. In this paper, we introduce and integrate the concept of substitutability of economic resources into a traditional bio-economic model. The results show that fishery management, which bases decisions solely on traditional bio-economic models where the dynamics and consequences of the operational decision processes of the industry are ignored, may reach decisions that work in opposition to their intended one.
\end{abstract}

Keywords: decision sciences, OR in natural resources, fisheries management, bio-economics, value of time, resource costs

Mathematics Subject Classification: 90B10, 90B90, 90B06

Submitted: August 6, 2020

Revised: December 22, 2020

C) 2020 Authors. This is an open access publication, which can be used, distributed and reproduced in any medium according to the Creative Commons CC-BY 4.0 License. License requiring that the original work has been properly cited.

\section{INTRODUCTION}

This paper will introduce a model using both the deductive methods ofbio-economics and merge it with an inductive method from decision sciences or operational research. The objective is to see if the two reasoning's are compatible within the one model and then explore what new information about fishery management the new approach reveals.

* Bifröst University, Department of Business, ÍS-311 Borgarbyggd, Iceland, corresponding author, e-mail: ingolfur@bifrost.is

** Reykjavik University, School of Science and Engineering, Menntavegi 1, 101 Reykjavik, Iceland, e-mail: pallj@ru.is 
Usually the bio-economic approach is credited to Gordon (1954) and Scott (1955) where they explore the relationships between fishing effort and the yield of a fish stock. Since then, the fishery literature, as well as fishery management in general, has focused on physical effort as a means to control the outtake from fishing stocks in an effort to maintain or achieve a "bio-economic equilibrium". In this context authors and fishery managers have focused on optimizing fishing fleet capacity (capital stock) were various technical specifications of the vessels are used as variables: Engine size, fish hold capacity, vessel size and number, see Smith and Hanna (1990). Then, the analyses have extended to include variables that can have indirect affects the capital stock, such as: vessel licenses, taxes, fishing time, quotas, etc., see for example Ólafsson et al. (2013).

It soon became evident that these models and methods were not sufficient as a vehicle to achieve "bio-economic equilibrium". It is therefore necessary to review and redesign the methods and models.

The next stage in the development of these models and methods was the introduction of a multi-species approach, see for example Flåten (1988). Squires (1987a, 1987b) and Squires and Kirkley (1991) studied the problem of regulating a "multiproduct" industry, where the products are, in fact, fish species. In the bio-economic approach the market dimension and multiple-product issue in the fishery management has been discussed largely in terms of multiple species and different attributes of individual fish stocks. The main focus has been on issues such as capital and various aspects of fleet dimensions. Little attention has been offered to actual processing costs, market prices and operational decisions facing economic agents in the industry. In this paper we will integrate a new and important dimension of the real-life decision problems into traditional bio-economic model and theoretically analyze the outcome.

Bjørndal et al. (2012) gives an overview of "Operation research in natural resource industry". In the chapter about fisheries, Bjørndal divides operation research in fisheries into four areas: bio-economic modeling, technical efficiency, fishermen's behavior and multi criteria decisions. An interesting issue here is that the author classifies bio-economic modeling as an operational research methodology and the same definition occurs in Árnason (2009).

These definitions are highly controversial because these models and methods have their basis in neoclassical economics. The economics are usually classified as deductive science, which starts out with a general statement, where assumptions such as the metaphors of equilibrium and bio-economic equilibrium play a central role. Models based on equilibrium theories are deductive and deterministic, where the dynamic behavior of agents along the various markets of the value chain are disregarded, from the fishing operations to the end consumers. Due to this over-simplified methodological approach, the approach therefore has an inherent potential to lead managers and decision makers to erratic conclusions and actions.

Fisheries can in large be characterized as a supply-driven as opposed to a demand-driven industry. This is due to environmental fluctuations that are beyond human control and impossible to predict. Long term planning is therefore in many cases unworkable and the decision on which product to produce and thus, what market segment to choose, literally must be taken as the fish is hauled onboard. At the moment 
of decision, the prices are fixed, and the decision maker can have little or no impact on them. The production decision has to be made momentarily in an ever-changing decision environment (Jensson, 1988).

In his optimization process, the decision maker will therefore focus on minimizing the cost of using available resources. In an ever-changing business environment, some resources may be abundant at one moment in time but scarce at another. For example, when landings are high and the raw material subject to decay, the agents will speed up production by processing the catch into lower-priced products. As a rule of thumb, the products that go faster through the production lines usually achieve lower market prices per unit of weight. By increasing the quantity at lower prices, they attempt to maintain an optimal net revenue in the given decision situation, see Arnarson and Johnston (1991). This behavior and practice are well known in industrialized fisheries (Iceland, Norway and the USA, for example).

Arnarson (2004) argues that given two resources, time and raw material for instance, that are at least partly substitutes, the decision-making in an economic process in time becomes relative. If the raw material (which we will call the reciprocal resource) in a given economic process in time becomes scarce, relatively to the time resource, the decision maker will tend to use less of it, and vice versa. The rationality behind this is as follows: As a resource becomes scarcer, it will be relatively more costly to use it in the process (compared to the reciprocal resources). In the case of two resources, time and raw material (fish quotas for example), a decision maker will predictably behave as follows: "When raw material is scarce the decision maker will produce the products that will give him the lowest costs per time unit, i.e. he will use more of the time resource. When time is scarce the economic agent will produce the products that will give him lowest costs per raw material unit, i.e. he will use more of raw material (quota)", see Arnarson (2004). In general: If the cost of one resource is high relative to the cost of the reciprocal resources, the decision maker will use relatively less of the scarce and expensive resource. This behavioral pattern can be seen in the fishing industries as described in Arnarson (2004), Arnarson and Jensson (2006), and in the paragraph above.

Let us consider a fish species, taking cod as an example. A broad range of fresh, salted and frozen products are produced from cod. The economic agent or a decision maker for a particular harvesting and production process can usually choose between several different products. Taking the production of fillets as an example, the main stages are gutting, heading, filleting, skinning, trimming, packing and freezing. There are a number of combinations leaving out one or more of these stages, leading to a variety of products. By skipping processing stages like trimming, the production rate can be increased (using relatively less of the time resource compared to the reciprocal resources), usually at the cost of a lower price per unit product. The products can then be sold to different market segments around the world, which usually have their own product specification that in turn adds to the variety of the possible portfolio of products.

The pattern described above can be seen in the Alaskan Pollock fishery, where the carcass can be processed into a number of products (surimi and various types of frozen products), requiring different input factors in the production process and 
sold to different market segments. In general, the sales price per unit for surimi is lower than for fillets. A kilogram of surimi is, however, produced in one third of the time that is required for one kilogram of fillets. Given that the fishery management of Alaska is based the "Olympic Fishery Management System" the decision makers will view the raw material (the fish) as "unlimited" relatively when compared to time in their production processes. Surimi production lines are more technologically advanced than fillet lines; they require more space and are usually more capital-intensive than investments in filleting operations. We could therefore expect that long running, relatively high market prices for surimi (compared to fillets) will contribute to capital stuffing in the surimi operation and increase the harvesting capacity of the fleet. The more labor-intensive filleting industry will lose ground and will get less of a share of the total quota under the Olympic System Management.

The consequences in the long run would be lower sales price per kilogram (poorer yield) and thus, less revenue for the total quota. Furthermore, we could expect lower grade of employment due to the fact that the surimi operation is less labor insensitive. Hence, cod for example, is not a single product in the economic process but a resource that has a great number of attributes. These attributes can in turn act as substitutes with other attributes of other resources within the process. To react to any changes in the operational environment, the decision makers will usually have several choices. Fishery management schemes will give the gridlines for the decision makers to operate within, and these gridlines will shape the overall operation of the industry, from investments in machines and facilities to products and market segments.

Árnason (2009) lists what he sees as number of well-defined objectives for fishery management. Among these objectives are: Maximum sustainable yield of a fish stock, conservation of fish stocks, generation of exports of and foreign exchange and maximum economic rent. Then Árnason states that: "Clearly, not all of these objectives are independent". In his paper Árnason (2009) assumes (as most of the bio-economical literature does) that there are dependencies between biomass of a stock and catch effort of a fleet. We will also incorporate this assumption in our model along with the inductive reasoning of decision sciences.

This paper proposes a modified fishery management bio-economic model that includes possible variations in the market prices and, thus, possible impacts thereof. In Section 3, we start with a simple harvesting model. To keep the presentation of our ideas clear, we will keep the line of argumentation as simple as possible. We introduce the operation- and market prices dimension to the harvesting model in Section 4 and add it to the model, which is then solved in Section 5. Section 6 deals with the question of fleet size. In Section 6 we give a practical illustration of the two model alternatives presented in Section 3 and 4. In Section 7, we will provide some concluding remarks.

\section{SIMPLE HARVESTING MODEL}

We will base our analysis on a traditional Gordon-Schaefer model, see for example, Hannesson (1974). The following analysis assume that the fleet is homogenous and harvesting a single stock of fish. That is, an analysis of a single vessel type that 
represents the rest of the fleet. All agents are alike and behaving rationally. In the following, ISK means Icelandic Kronur. To start, the following notation is introduced:

$I Q$ : individual vessel quota (tons/year),

$P_{C}$ : maximum product and harvesting capacity for the vessel (tons/year),

$n$ : number of vessels,

$E$ : total annual effort for all vessels, operation time at sea (days),

$Y$ : yield, or annual harvest, a function of $E, Y(E)$ (tons/year),

$P$ : sales prices for the finished products (ISK/ton),

$C_{E}$ : cost associated with each unit of effort (ISK/day at sea),

$C_{F}$ : cost associated with each vessel ISK/vessel/year),

$C R$ : catch rate. Quantity per unit effort where $C R(E)=Y(E) / E$ (tons/day),

$e$ : upper limit on annual effort per vessel, i.e. maximum time at sea per year for each vessel (days),

$Z$ : net revenue, i.e., sales price*yield - costs (ISK/year).

As argued above, we assume that the decision makers in the economic processes of the fisheries are price takers. The quantity of fish harvested and produced has no impact on the market prices. We furthermore assume that the cost of fishing is a linear function of $E$ and $n$. We can make this assumption because the decision makers in the fishing operation are going after a single species. The cost of harvesting will be the same whatever product the respective species will be made into afterwards.

Then, the optimal effort is found by solving Model 1 , assuming $I Q \leqslant P_{C}$ :

$$
\begin{array}{ll}
\operatorname{Max} & Z=P \cdot Y(E)-C_{F} \cdot n-C_{E} \cdot E \\
& E \leqslant e \cdot n \\
& I Q \cdot n=Y(E) \\
& E, n, I Q \geqslant 0 \quad n \text { integer }
\end{array}
$$

Let us also define the average catch rate, $C R$ (average yield per unit effort) as follows:

$$
C R(E)=Y(E) / E
$$

When solving Model 1, it becomes evident that $n$ should always be as small as possible (Ex. (2)), and the individual quota $I Q$ accordingly as large as possible (Ex. (3)), that is

$$
n=E / e \text { in Ex. (2), and } I Q=e \cdot C R(E)
$$

Keeping this in mind, and again assuming that the catch rate will be the limiting factor rather than production capacity, i.e. $I Q \leqslant P_{C}$, we get a well-known solution to Model 1 (see for example Hannesson (1974) and Figure 1):

$$
P \cdot Y^{\prime}(E)=\left(C_{E}+C_{F} / e\right)=>E 1 \text { and } Z 1\left(\text { and } n 1 \text { and } I Q_{1}\right)
$$

Let us assume the scenario of an open access fishery in a state of equilibrium at point a as shown in Figure 1, at an effort level $E_{2}$, with $n=E_{2} / e$ vessels participating. By using Model 1, we see that the optimal action is to reduce the number of vessels 
to $n_{1}=E_{1} / e$ (which is equal to maximum bio-economic yield), with each vessel harvesting at an individual quota level equal to $I Q_{1}=e \cdot C R\left(E_{1}\right)$.

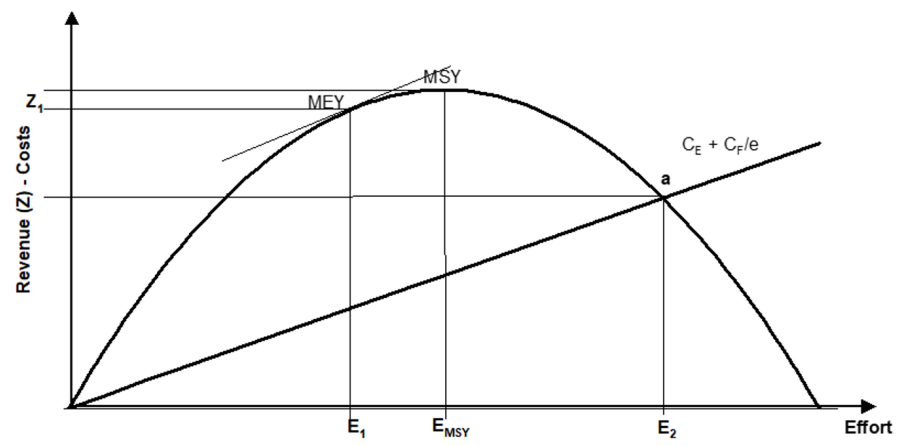

Fig. 1. A Gordon-Schaefer Model, a bio-economic equilibrium. MSY: Maximum Sustainable Yield, MEY: Maximum Economic Yield

\section{ADDING OPERATIONS AND MARKET PRICES}

As stated before we will keep the model as simple as possible and thus we repeat that we assume that the fishing fleet is homogenous, i.e., all vessels are exactly equal. We can express this as follows:

$$
I Q \cdot n=T A C
$$

where $I Q$ stands for the individual quota, $n$ for number of vessels in the fleet and $T A C$ for Total Allowable Catch (tons/year).

Treating the number of vessels in the fleet as a continuous variable, we will get a continuous function. Given a continuous number of vessels, the $I Q$ 's will also be a continuous number.

To simplify our analysis, we assume that a single type of a factory trawler is representative of a fishing industry. Furthermore we assume, based on Arnarson (2004) and Arnarson and Jensson (2006), where a dynamic simulation of factory trawler operation was used, that the natural fluctuations of input factors, such as catch rates, will change the relative cost of available resources in the production process. Fluctuation of the catch rates will for example change the value of that resource relatively to the time resource. This effect can also be magnified by increasing the amount of quota $I Q$ allocated to each production unit. Arnarson and Jensson (2006) showed that by simulating increase in a quota for given technical unit for a given period, the average prices will gradually decline in a familiar concave manner or what is commonly named the law of diminishing returns. We therefore assume that the revenue as a function of increased vessel quota has a concave form. This is shown in Figure 2, where the revenue $R$ of a fishing industry (fishing vessel) is shown as a function of quota $I Q$. 


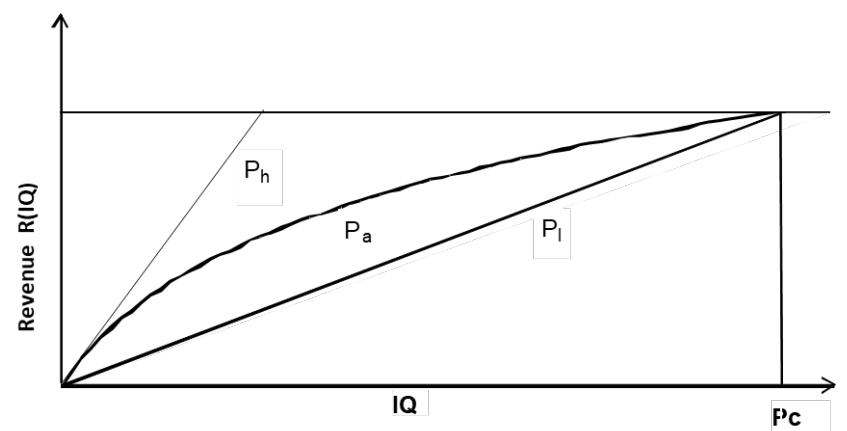

Fig. 2. Revenue for an economic process in a fishing industry. $P_{h}$ : highest price, $P_{a}$ : average price, $P_{l}$ : lowest price, IQ: quota per unit, Pc: production capacity

In Figure 2 we have dropped the assumption of a single sales price $P$ and introduced a range of products and prices, such that

$P_{h}$ - price for most valuable and, at the same time, most labor-intensive product. This would be the only product produced in the case of a very small annual quota, that is, relatively high cost of raw material compared to the time resource.

$P_{l}$ - price for the least valuable, but "fastest", product. This would be the only product produced in the case of the maximum possible quota $I Q=P c$, that is, relatively high cost of the time resource compared to the cost raw material.

$P_{a}$ - average price or actual sales price obtained by the process. The sales prices of each product are constants as described above, however the product mix changes with increasing $I Q$. See Arnarson, Jensson (2006).

The revenue function $R(I Q)$ increases first marginally by $P_{h}$, but eventually the marginal increase becomes zero, when the production capacity, $P c$, of the industry is reached.

From Figure 2, we can now deduct a general form for the average price $P_{a}$ and the average marginal price $P_{m}$ at each quota level $I Q$, see Figure 3 .

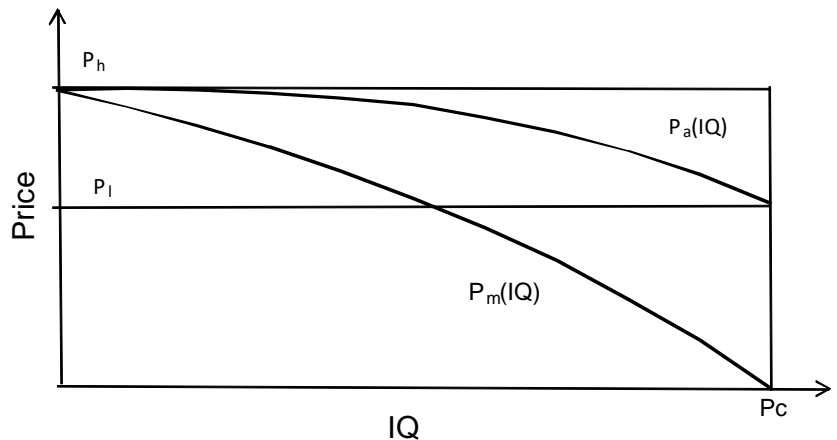

Fig. 3. Average and marginal price in an economic process. $P_{h}$ : highest price, $P_{a}$ : average price, $P_{l}$ : lowest price, IQ: quota per unit, Pc: production capacity 
Instead of our previous harvesting Model 1, we now have Model 2:

$$
\begin{array}{ll}
\operatorname{Max} & Z=P_{a}(I Q) \cdot Y(E)-C_{F} \cdot n-C_{E} \cdot E \\
& E \leqslant e \cdot n \\
& I Q \cdot n=Y(E) \\
& I Q \leqslant P c \\
& e \cdot C R(E) \leqslant P c \\
& E, n, I Q \geqslant 0, \quad n \text { integer }
\end{array}
$$

The main difference between Models 1 and 2 is that the average sales price is no longer fixed, which is sufficient to cause $n$ and $I Q$ no longer to have trivial solutions, as will be seen in the next section.

\section{DETERMINING THE OPTIMAL QUOTA}

To solve Model 2, we first eliminate $\mathrm{n}$ using (2.3), which gives

$$
\begin{array}{ll}
\operatorname{Max} & Z=\left[P_{a}(I Q)-C_{F} / I Q\right] \cdot Y(E)-C_{E} \cdot E \\
& I Q \leqslant e \cdot C R(E) \\
& I Q \leqslant P c \\
& E, I Q \geqslant 0
\end{array}
$$

By relaxing Expression (15), i.e., the upper limit on $I Q$ by using Expression (16), Model 2 can be solved in two steps. We base our validation on relaxing the upper limit of Expressions (15) on findings by Arnarson and Jensson (2006), where it was shown by simulations that the maximum quota is not necessarily the optimum one, and also on the calculations in Section 6 of this paper.

Step 1: Determine $I Q=I Q_{\text {opt }}$ by maximizing the "net price", $P_{n}(I Q)$ :

$$
\begin{array}{ll}
\operatorname{Max} & P_{n}(I Q)=\left[P_{a}(I Q)-C_{F} / I Q\right] \\
& 0 \leqslant I Q \leqslant P c
\end{array}
$$

It is important to note that under this assumption (relaxation of Expressions (15)), determining the optimal quota $I Q_{o p t}$ is independent of determining the effort $E$ and the harvest $Y(E)$. This becomes obvious when scrutinizing this from the biological point of view. The market prices cannot have an impact on the growth of wild species. The determination of the MSY and therefore the quantity that is allowed to catch from a given stock is totally independent of the sales prices.

Figure 4 shows how $I Q_{o p t}$ is found. 


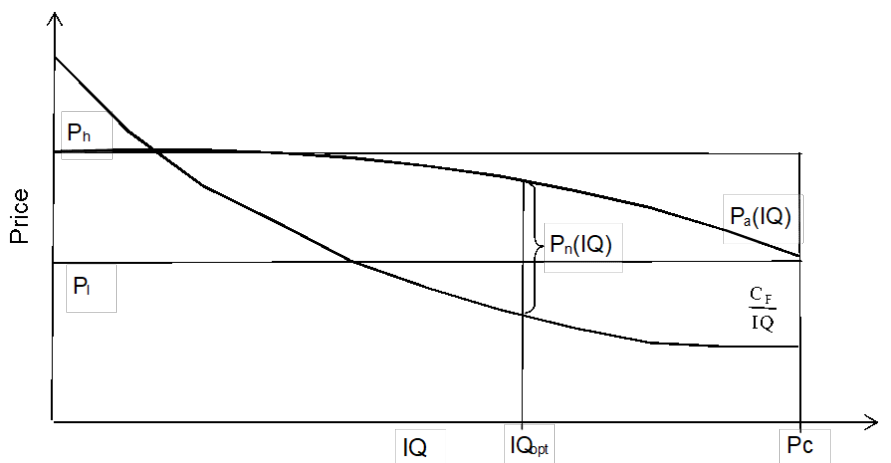

Fig. 4. Optimal allocation of fishing quota. $P_{h}$ : highest price, $P_{a}$ : average price, $P_{l}$ : lowest price, IQ: quota per unit, Pc: production capacity, $P_{n}$ : net price, IQ $Q_{\text {opt }}$ : optimal quota, CF: annual fixed operation cost per unit

The solution is derived from:

$$
I Q_{o p t}=S Q R T\left(C_{F} /\left(-P_{a}^{\prime}\left(I Q_{o p t}\right)\right)\right.
$$

The second step of Model 2 is as follows:

Step 2: Determine the optimal effort $E$ on the basis of $I Q_{o p t}$ and $P_{n}\left(I Q_{o p t}\right)$

$$
\begin{aligned}
\operatorname{Max} \quad Z & =P_{n}\left(I Q_{o p t}\right) \cdot Y(E)-C_{E} \cdot E \\
E & \geqslant 0
\end{aligned}
$$

resulting in the solution

$$
P_{n}\left(I Q_{o p t}\right) \cdot Y^{\prime}(E)=C_{E} \Rightarrow E_{o p t}
$$

To conclude this section, we emphasize that the question of how much quota should be allocated to each vessel can be separated from the determination of the rate of harvesting the fish stock, or in other words the determination of Total Allowable Catch TAC. Determining the size of the individual quota for each factory trawler only depends on the products, the market prices and the production attributes of the products and the annual operation cost of the trawler $C_{F}$.

\section{DETERMINING FLEET SIZE}

It can be shown that, when comparing the solutions to Model 1 and Model 2, the following is true under reasonable assumptions (for the annotation $Z_{1}$ and $E_{1}$, see Figure 1):

$$
n_{\text {opt }}>n, I Q_{o p t}<I Q_{1}=P c, E_{\text {opt }}>E_{1} \text { and } Z_{\text {opt }}>Z_{1}
$$

Therefore, taking the concavity of the average price curve $P_{a}(I Q)$ into account, more vessels than earlier concluded from Model 1 should be operated with less than the maximum quota each, resulting in a higher rate of harvesting and returns. 
Turning back to the scenario discussed at the end of Section 3, it should now be clear that reducing the fleet to as few vessels as possible may not be an optimal solution. It may even not be better than keeping the present number of vessels in a given fishery unchanged but imposing individual quotas of appropriate size.

Let us briefly study the impact of quota allocations on fleet size, after the effort $E$ and total yield $Y$ have been predetermined, i.e., $T A C=Y(E)$ is given. By inserting $I Q=T A C / n$ into model (2), we get Model 3:

$$
\begin{array}{ll}
\operatorname{Max} & Z(n)=P_{a}(T A C / n) \cdot T A C-C_{F} \cdot n \\
& n \geqslant 0 \quad n \text { integer }
\end{array}
$$

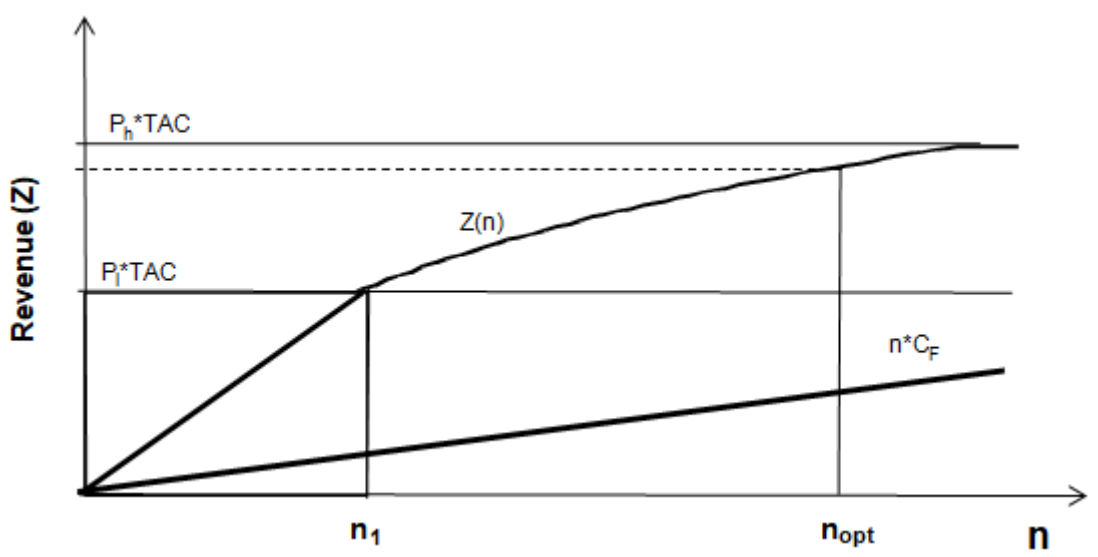

Fig. 5. Gross revenue for an economic process. $P_{h}$ : highest price, $P_{l}$ : lowest price, $n:$ number of vessels, $n_{\text {opt }}$ : optimal vessel number, $C F$ : annual fixed operation cost per unit, $Z$ : revenue, TAC: total allowable catch

For a fleet not capable of fishing their quota $(I Q)$, usually the case for open access fishery management systems or for a fleet which $I Q$ is exactly at the technical capacity, the agents will regard the fish resource as unlimited and therefore relatively cheap, compared with other input factors (resources). Consequently, the time resource becomes relatively scarce and the cost of the time resource becomes relatively high. The decision makers in the fleet will therefore try to put as much as possible through the production lines in the shortest possible time, resulting in producing the cheapest and "fastest" products up to point $\mathrm{n} 1$. The slope of the revenue curve on this interval (zero to $n_{1}$ ) will therefore be linear. Increasing the fleet beyond $n_{1}$ on Figure 5, will increase the availability of the time resource, compared with other input resources in the process, such as raw material (fish stock). The cost of time will gradually decrease relatively to the cost of other resources, which in turn encourages agents to use relatively more of it in the process. The result is the gradually increased production of higher-priced products until the optimum is reached at $n_{\text {opt }}$. 


\section{AN ILLUSTRATION}

The numbers in the following example are not from any particular fishing industry but are adopted from Arnarson and Jensson (2004) and are purely for illustration.

Let us consider a fishing industry with the characteristics represented by the input values in Table 1.

Table 1. Input values, Models 1 and 2

\begin{tabular}{|l|c|c|}
\hline \multicolumn{1}{|c|}{ Parameter } & Symbol & Value \\
\hline Average sales price (Model 1) & $P$ & $200 \mathrm{ISK} / \mathrm{kg}$ \\
\hline Sales price, calculated (Model 2) & $P(I Q)$ & $=300-I Q^{2} / 450 \mathrm{ISK} / \mathrm{kg}$ \\
\hline Cost associated with each vessel & $C_{F}$ & $10,000,000 \mathrm{ISK}$ \\
\hline Cost associated with unit of effort & $C_{E}$ & $50,000 \mathrm{ISK}$ \\
\hline Upper limit on annual effort & $e$ & 300 days \\
\hline Yield, calculated & $Y(E)$ & $=\left(1,000,000-(E-1,000)^{2}\right) \mathrm{kg}$ \\
\hline
\end{tabular}

The input values in Table 1 are then fed into Model 1 and Model 2, as defined in the previous sections. The results are shown in Table 2.

Table 2. Output values, Model 1 and 2

\begin{tabular}{|l|c|c|c|c|}
\hline \multicolumn{1}{|c|}{ Parameter } & Symbol & Model 1 & Model 2 & Difference [\%] \\
\hline Gross rev (mill ISK) & - & 194 & 257 & 32 \\
\hline Cost (mill ISK) & - & 90 & 118 & 31 \\
\hline Net rev (mill ISK) & $Z$ & 104 & 139 & 34 \\
\hline No vessels & $n$ & 4.9 & 7.5 & 53 \\
\hline Effort (days) & $E$ & 833 & 865 & 4 \\
\hline Quota (metric tons) & $I Q$ & 200 & 131 & -35 \\
\hline Price (average in ISK/kg) & $P(I Q)$ & 200 & 262 & 31 \\
\hline Yield & $Y(E)=n \cdot I Q$ & 980 & 983 & 0 \\
\hline Catch rate & $C R(E)=Y / E$ & 1.18 & 1.14 & -3 \\
\hline Gross rev/vessel (mill ISK) & - & 39.6 & 34.3 & -13 \\
\hline Net rev/vessel (mill ISK) & $Z / n$ & 21.2 & 18.5 & -13 \\
\hline
\end{tabular}

As stated in Section 5, we would anticipate that the results from Model 2 would show a higher harvesting rate than Model 1, as shown in Table 2, see $E$ and $Y(E)$. Still, the harvesting rate is on the left side of the Maximum Sustainable Yield, MSY (see Fig. 1). Furthermore, the number of vessels is larger in the model that has been linked to sales prices than the model that is not ( $n$ in Table 2$)$. Despite this, the net revenue $(Z)$ is $34 \%$ higher for Model 2 than the results from Model 1, and the gross revenue from Model 2 is also higher $(32 \%)$. 


\section{CONCLUDING REMARKS}

Given that the agenda of a policy maker is to optimize the level of economic activity in a given area or for a given society, the policy based on Model 1, which is the common model for contemporary management schemes, is socio-economically less efficient than a policy based on Model 2. In fact, as stated before, the policy based on Model 1 may yield a result opposite to the intention of the policy maker. This discrepancy between the socio-economic optimum and the optimum for individual firms (vessels) can be deducted from Table 2. By choosing a policy based on Model 2 instead of Model 1, the net revenue for each individual unit (fishing vessel) in the industry is reduced. The results state clearly that there exists a socio-economic optimum and an optimum for each individual vessel, and that these optima may not be compatible. In other words: "Aggregated optimal revenue for individual economic agents may collide with optimal economic revenue for a society".

These findings can be of vital importance for fishery dependent areas and their societies. We often find fishery dependent areas in remote and more sparsely populated parts of the world, such as Northern Norway, Iceland, Newfoundland, and Alaska. The areas were populated because of the presence of the fish resources and the communities developed on basis of those same resources. Along with the fisheries, secondary and tertiary industries developed but for the most part these areas are still dependent on whether the fisheries prosper. The dependency of secondary and tertiary industries on fisheries are amplified by the fact that opportunities for additional or new industries are limited or non-existent in these remote areas. Poorly founded or faulty fishery management decision can lead to the depopulation of these areas, which in turn can have costly social implications along with the economic factors.

In Section 5 we concluded that the optimal quota per vessel from a given fish stock could be determined separately from the determination of the biological yield and fishing effort of that same stock. The optimal quota and the capacity of the industry can be determined independently. The merging of these methods is therefore not necessary and can in fact contribute to misleading and confusing fishery managers in their decision process.

The objective of biological agents and economic agents differ. On the one hand, they are concerned with optimizing the biomass of a given fish stock or to find the Maximum Sustainable Yield. On the other hand, the objective of economic policies is to allocate available resources between economic agents. Economic agents may then have different objectives or policies. What is optimized, and how, also depends on the ruling policies (laws and regulations) and who are allowed to participate. The very nature of neo-classical modeling is that every decision maker in the model has the same underlying objective or policies (equilibrium). We have proven that this does not necessarily lead to optimal decision-making in a real-life environment.

Although the analysis in this paper is concentrated around fishery issues, it has broader applications. We assume that the behavior of economic agents and their use of resources as described in this paper are common, although they may be more prominent within fisheries due to the high degree of variations in the operational environment. We therefore anticipate that the scope of the suggested improvement 
of methods and models presented in this paper has a more general application, most apparently within industries with renewable resources such as agriculture and forestry.

\section{REFERENCES}

Arnarson, I., 2004. Analyzing Behavior of Agents of Economic Processes in Time. Working paper series. W-Series, Institute of Economic Studies, University of Iceland, Reykyavik.

Arnarson, I., Jensson, P., 2006. Impact of the cost of the time resource on efficiency of economic processes. European Journal of Operational Research, 172(2), pp. 616-630.

Arnarson, I., Johnston, R.S., 1991. Modeling Groundfish Supply. A Linear Programming Approach with Application to Newfoundland. In: Schranck, W. (ed.), Econometric Modelling of the World Trade in Groundfish. Springer, Dordrecht, Netherlands, pp. 73-82.

Árnason, R., 2009. Fisheries management and operations research. European Journal of Operational Research, 193(3), pp. 741-751.

Bjørndal, T., Herrero, I., Newman, A., Romero, C., Weintraub, A., 2012. Operations research in the natural resource industry. International Transactions in Operational Research, 19(1-2), pp. 39-62.

Flåten, O., 1988. The Economics of Multispecies Harvesting - Theory and Application to the Barents Sea Fisheries. Studies in Contemporary Economics. Springer-Verlag, Berlin Tokyo.

Gordon, H.S., 1954. The Economic Theory of a Common Property Resource: The Fishery. Journal of Political Economy, 62, pp. 124-142.

Hannesson, R., 1974. Economics of Fisheries: Some Problems in Efficiency. Lund University, Lund.

Jensson, P., 1988. Daily Production Planning in Fish Processing Firms. European Journal of Operations Research, 36(3), pp. 410-415.

Ólafsson, A., Margeirsson, S., Ásgeirsson, E.I., Stefánsson, H., Jensson, P., Guãmundsson, R., Arason, S., 2013. Quantitative Methods for Decision Support in the Icelandic Fishing Industry. Natural Resource Modeling, 26(3), pp. 365-384.

Scott, A., 1955. The Fishery: The Objectives of Sole Ownership. Journal of Political Economy, 63, pp. 116-124.

Smith, C.L., Hanna, S.S., 1990. Measuring Fleet Capacity and Capacity Utilization. Canadian Journal of Fisheries and Aquatic Sciences, 47(11), pp. 2085-2091.

Squires, D., 1987a. Public Regulation and Structure of Production in Multiproduct Industries: An Application to the New England Otter Trawl Industry. RAND Journal of Economics, 18(2), pp. 232-247.

Squires, D., 1987b. Long-Run Production Function for Multi-Product Firms. American Journal of Agricultural Economics, 18(3), pp. 558-569.

Squires, D., Kirkley, J., 1991. Production Quota in Multiproduct Pacific Fisheries. Journal of Environmental Economics and Management, 21(2), pp. 109-126. 